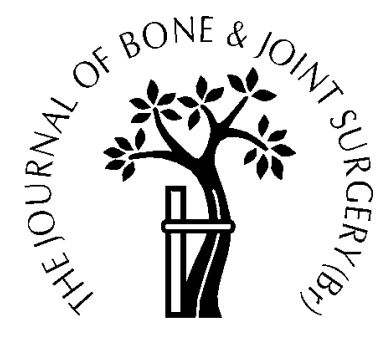

\title{
Fracture of the carpal scaphoid
}

\author{
A PROSPECTIVE, RANDOMISED 12-YEAR FOLLOW-UP \\ COMPARING OPERATIVE AND CONSERVATIVE TREATMENT
}

\author{
B. Saedén, H. Törnkvist, S. Ponzer, M. Höglund \\ From Stockholm Söder Hospital, Stockholm, Sweden
}

W e compared the long-term outcome in 61 patients (62 fractures) treated operatively or conservatively for an acute fracture of the carpal scaphoid. A total of $\mathbf{3 0}$ fractures was randomised to conservative treatment using a cast and 32 to operative treatment using a Herbert bone screw.

The duration of sick leave was shorter for patients treated by operation, but this was only significant in patients with blue-collar occupations. There were no differences between the groups in respect of function, radiological healing of the fracture, or carpal arthritis after follow-up at 12 years. Those managed by operation showed radiological signs of arthritis of the scaphotrapezial joint more often, but this finding did not correlate with subjective symptoms.

Operative treatment of an acute fracture of the scaphoid allows early return of function and should be regarded as an alternative to conservative treatment in patients in whom immobilisation in a cast for three months is not acceptable for reasons related to sports, social life or work.

J Bone Joint Surg [Br] 2001;83-B:230-4.

Received 27 March 2000; Accepted after revision 25 August 2000

The scaphoid is the carpal bone which is fractured most frequently, often in people of working age. The treatment of choice is generally accepted as immobilisation of the wrist in a short-arm cast for ten to 12 weeks. Sometimes, this period has to be prolonged, particularly when the proximal pole is involved. The incidence of nonunion is reported as between $5 \%$ and $12 \%$ in conservatively-treated fractures. ${ }^{2-4}$ Primary osteosynthesis was suggested as an alternative but, initially, technical difficulties at surgery and nonunion were

B. Saedén, MD, Head of Upper Extremity

H. Törnkvist, MD, Head of Trauma

S. Ponzer, MD, Consultant Orthopaedic Surgeon

Department of Orthopaedics

M. Höglund, MD, Consultant Radiologist

Department of Radiology

Stockholm Söder Hospital, S-118 83 Stockholm, Sweden.

Correspondence should be sent to Dr B. Saedén.

(C)2001 British Editorial Society of Bone and Joint Surgery 0301-620X/01/211197\$2.00 major problems. In 1984, Herbert and Fisher ${ }^{5}$ published their experiences with a new type of screw, the use of which is now established in the treatment of acute fracture as well as in nonunion of the scaphoid. The short-term results of such fractures treated surgically are generally good, but the long-term outcome is not as well established. $^{2,5-7}$ We have compared the long-term results in patients with fracture of the scaphoid treated by immobilisation in a short plaster cast with those treated acutely by fixation by a Herbert screw.

\section{Patients and Methods}

Between 1984 and 1986 we randomised 61 patients with 62 acute fractures of the scaphoid to alternative treatments. We treated 32 fractures operatively using a Herbert screw (Fig. 1) and 30 conservatively by a short-arm cast. Only patients with an acute fracture visible at the first radiological examination were included. We excluded those with a fracture through the tuberosity of the scaphoid and those with radiological signs of delayed union or pseudarthrosis. The study was approved ethically and the patients gave their informed consent to participate. There were no demographic differences between the two groups (Table I). The mean age at the time of the injury was $29 \pm 13$ years for those undergoing operation and $37 \pm 20$ years for the conservatively-treated group. The dominant hand was injured in $11(34 \%)$ of the patients treated by surgery and in 11 $(37 \%)$ of those who received conservative treatment. Neither the type of fracture nor the mechanisms of injury differed significantly between the groups. The delay from injury to treatment was $12 \pm 5$ days for the operated patients and $5 \pm 11$ days for those treated conservatively, which was also not significant.

Treatment. The operative treatment was carried out as described by Herbert and Fisher ${ }^{5}$ by two surgeons using a volar approach with a tourniquet, 22 under general anaesthesia and ten under brachial plexus block. The mean operating time was 54 minutes. The two surgeons were BS and another who did not participate in the study. In all fractures, the Herbert screw was inserted from the distal pole of the scaphoid after entering the scaphotrapezial joint. In one case, bone graft was used because of significant loss of bone at the site of the fracture. One patient had operative 


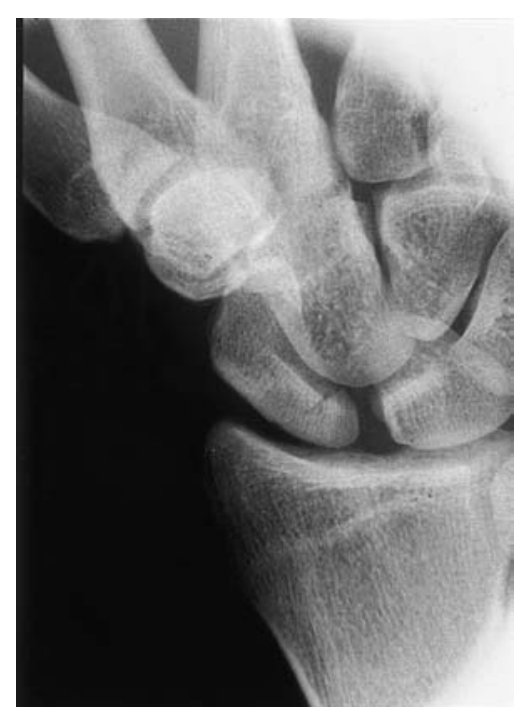

Fig. 1a

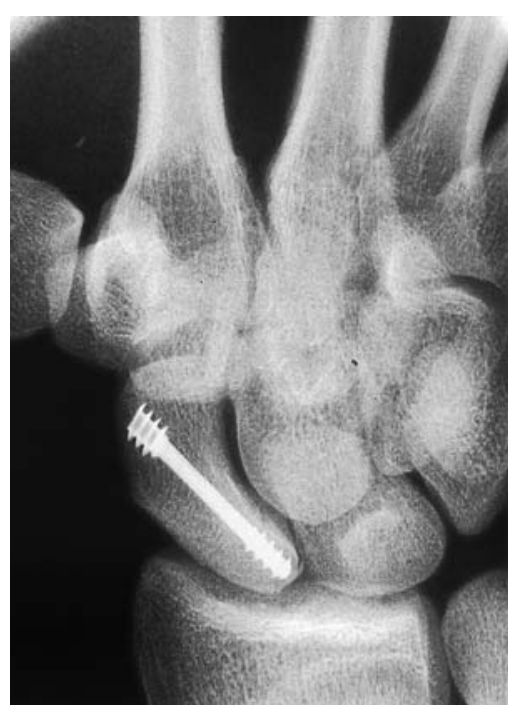

Fig. 1b treatment in 1984 and two years later had a fracture of the contralateral scaphoid which was treated conservatively, after randomisation. The patients in the operated group were in hospital for a mean of 1.6 days and wore a Colles' type plaster cast for two weeks. Patients treated conservatively wore a short-arm cast (from below the elbow to

Table I. Details and characteristics of the injury in the 32 wrists treated by operation and the 30 treated conservatively, by number and percentage

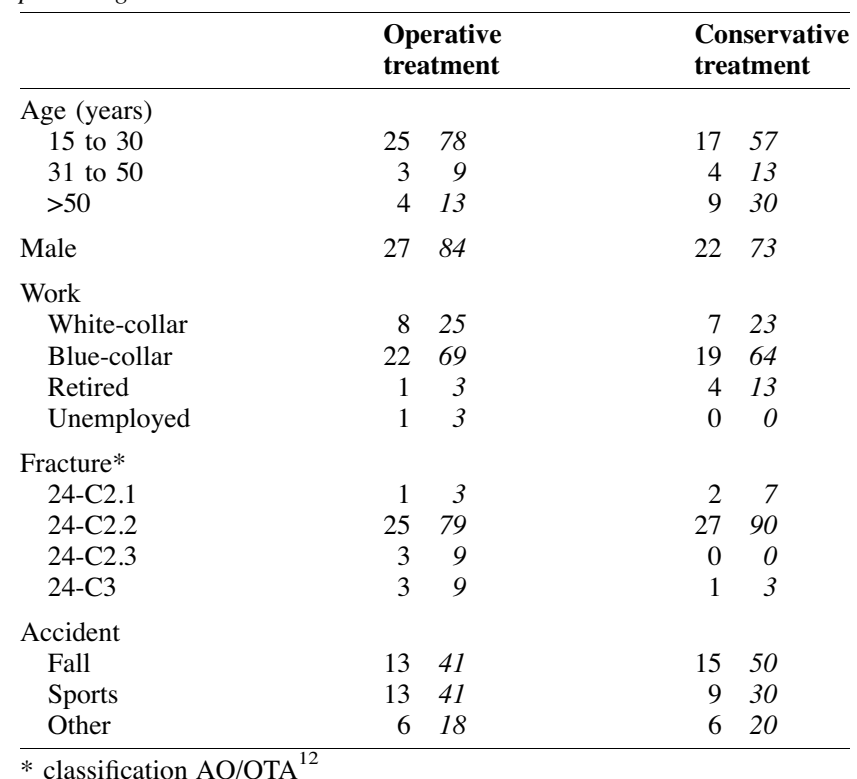

Table II. The number of patients and wrists reviewed at the 12-year follow-up

\begin{tabular}{llll}
\hline & $\begin{array}{l}\text { Operative } \\
\text { treatment } \\
\text { (n= 32 wrists) }\end{array}$ & $\begin{array}{l}\text { Conservative } \\
\text { treatment } \\
\text { (n= 30 wrists) }\end{array}$ & $\begin{array}{l}\text { Patients } \\
\text { (n= 61) }\end{array}$ \\
\hline Questionnaires & 25 & 26 & 50 \\
Physical examination & 25 & 23 & 47 \\
Radiography/CT & 24 & 19 & 42 \\
\hline
\end{tabular}

the metacarpophalangeal joints of the fingers and to the interphalangeal joint of the thumb) until the fracture showed radiological signs of union.

Follow-up. The patients were followed up clinically reviewing tenderness, range of movement, strength and radiologically until the fracture united. The duration of sick leave was recorded. At 12 years (mean, $11.7 ; 10.2$ to 12.8 ) after the injury, all patients were contacted by mail. A total of 50 patients with 51 fractures $(82.3 \%$ ) (25 treated by surgery and 26 conservatively) agreed to participate in the follow-up. Three patients had died and eight could not be located. Table II shows those patients participating in the questionnaire, physical examination, and radiological review at the 12-year follow-up. Figure 2 shows the questionnaire which we used for rating subjective symptoms. In the first part, patients were asked if they had any symptoms related to the scaphoid fracture, and, in the second, to rate the level of symptoms on a visual analogue scale from 0 to 10. Physical examination included the range of extension and flexion of the wrist which was measured by a goniometer, and grip strength which was measured by a Martin Vigorimeter (Martin Medizin-Technik, Tuttlingen, Germany), for both the injured and uninjured wrists. When calculating the differences between the injured and uninjured wrists compensation was made for asymmetrical grip strength relating to hand dominance.

Radiological review included plain radiography and bilateral CT which allowed a comparison between the radiographs before operation and at 12 years after the fracture, as well as between the injured and uninjured sides. Healing of the fracture and osteoarthritis of the carpal and scaphotrapezial joints were evaluated by an independent radiologist. Osteoarthritis was defined as narrowing of the joint or reactive changes around it compared with the uninjured side.

Statistical analysis. Differences between the groups were tested by the two-tailed Student's $t$-test for independent 
Do you experience pain or discomfort from your previously injured wrist?

1. Never

2. At strenuous exercise

3. At minor excercise

4. Continuous symptoms

Please rate the level of your symptoms on the lines below 10 10)

1. How often do you have pain in your injured wrist? (never always)

2. How much pain do you have? (none maximum pain)

3. Do you have pain during the night-time? (never always)

4. Do you have pain at the end of the day? (never always)

5. Does your wrist feel stiff in the morning? (never always)

6. Do you have problems with wrist movement? (never always)

7. Do you have problems carrying things? (never always)

8. Do you have problems performing manual work with your arm? (never always)

9. Please, rate the total outcome level of your hand function (perfect worst possible)

Fig. 2

Questionnaire used for the assessment of outcome 12 years after the injury.

groups. Differences beween distributions were tested by the chi-squared test for independence; in the case of small groups, Fisher's exact test was used. The results were considered to be significant if $\mathrm{p}<0.05$.

\section{Results}

A short-arm cast was worn by the patients treated operatively for a period of $2 \pm 1$ weeks and by those treated conservatively for $12 \pm 3$ weeks $(\mathrm{p}<0.01, \mathrm{t}=-15.7)$. The 24 patients treated by surgery and who were working at the time of the injury were on sick leave for an average of $6 \pm$ 3 weeks compared with $15 \pm 10$ weeks in the 21 treated conservatively $(\mathrm{p}=0.002, \mathrm{t}=-3.77)$. Patients with a bluecollar occupation were on sick leave for a mean period of 7 \pm 3 weeks in the operated group and for $18 \pm 9$ weeks in those treated conservatively $(\mathrm{p}<0.01, \mathrm{t}=-4.3)$. The corresponding periods of sick leave for patients with a whitecollar occupation were $2 \pm 2$ and $5 \pm 6$ weeks, respectively, which was not significantly different.

Two of the 30 fractures among conservatively-treated patients were regarded as ununited after five and six months. They were operated on later using a Herbert screw without bone graft. One was found to be stable at the time of surgery but radiologically unhealed. Both fractures eventually united. One year after surgery one of the patients in the operated group had a nonunion visible on plain radiographs, but no subjective symptoms and therefore had no further treatment. In two patients the Herbert screw was removed, in one of the early cases because the screw did not enter the proximal fragment, and in the other because of radiological signs of loosening of the screw and suspected nonunion. Both fractures were found to be healed at the second procedure. No wound infections or other operative or postoperative complications occurred in the operated group.

At 12 years after the fracture, 20 of the patients $(80 \%)$ who had surgery and 18 of those treated conservatively $(69 \%)$ reported no pain or discomfort in the wrist (Table III).

Using the visual analogue scale most patients rated their symptoms at less than one, those who had operations being slightly lower than those who had not.

The grip strength of the injured hand was 95\% compared with the uninjured hand among the operated patients and $88 \%$ among those not operated upon. The range of movement was $96 \%$ of the uninjured side in the operated group and $98 \%$ in the conservatively-treated group. Neither difference was significant.

The radiographs at follow-up at 12 years showed that all fractures had united. Three patients were excluded from the final analysis; one had bilateral fractures and two who had initially been treated conservatively required surgery during the period of follow-up. As shown in Table IV, 18 of the 39 wrists evaluated showed established arthritis of the scaphotrapezial joint on CT compared with the uninjured side (Fig. 3). Six of these patients reported symptoms affecting their work or leisure activities. Five other patients complained of symptoms but showed no radiological signs of osteoarthritis of the scaphotrapezial joint. Radiological evidence of osteo- 
Table III. The patients' rating of pain and discomfort at the 12-year follow-up, by number and percentage

\begin{tabular}{lcccc}
\hline & $\begin{array}{l}\text { Operative } \\
\text { treatment } \\
(\mathbf{n = 2 5 )}\end{array}$ & $\begin{array}{l}\text { Conservative } \\
\text { treatment } \\
(\mathbf{n = 2 6 )}\end{array}$ \\
\hline Never & 20 & 80 & 18 & 69 \\
At strenuous exercise & 4 & 16 & 5 & 19 \\
At minor exercise & 1 & 4 & 3 & 12 \\
Continuous symptoms & 0 & 0 & 0 & 0 \\
\hline
\end{tabular}

Table IV. CT evaluation of osteoarthritis of the scaphotrapezial and of the radiocarpal joints, by number and percentage

\begin{tabular}{lrrrr}
\hline & $\begin{array}{l}\text { Operative } \\
\text { treatment } \\
(\mathbf{n = 2 3 )}\end{array}$ & $\begin{array}{l}\text { Conservative } \\
\text { treatment } \\
(\mathbf{n = 1 6})\end{array}$ \\
\hline Scaphotrapezial & & & & \\
$\quad$ None & 9 & 39 & 12 & 75 \\
None (with complaints) & 2 & 22 & 3 & 25 \\
Yes & 14 & 61 & 4 & 25 \\
Yes (with complaints) & 3 & 21 & 3 & 75 \\
Radiocarpal & & & & \\
None & 14 & 61 & 11 & 69 \\
None (with complaints) & 3 & 21 & 5 & 45 \\
Yes & 9 & 39 & 5 & 31 \\
Yes (with complaints) & 2 & 22 & 2 & 40 \\
\hline
\end{tabular}

arthritis at this site was more common among patients in the operated group compared with those treated conservatively ( $p=0.049$, Fisher's exact test), but these signs of scaphotrapezial arthritis were not related to symptoms. There were no significant differences between the groups in respect of osteoarthritis of the radiocarpal joint.

\section{Discussion}

Immobilisation of the wrist in a plaster cast is a safe and reliable method of treating acute fractures of the carpal scaphoid, since $90 \%$ to $95 \%$ will heal. ${ }^{9,10}$ It is difficult, however, for many patients to accept time-consuming

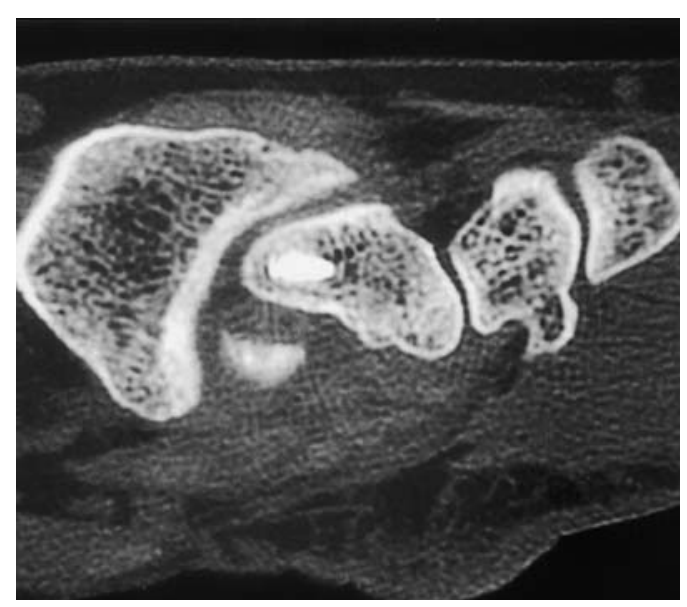

Fig. 3a immobilisation in a plaster cast with subsequent rehabilitation. A displaced fracture, delayed presentation of the fracture, nonunion, and a fracture with associated injuries are generally accepted as indications for operation. ${ }^{11}$ Since new and safer operative techniques have been developed, the choice between non-surgical and surgical treatment has become less clear.

In our study the fractures united whether they were treated operatively or conservatively. No significant complications occurred in those undergoing operation, confirming that treatment by a Herbert screw is a safe procedure if carried out by an experienced surgeon. One disadvantage of using the Herbert screw is that the scaphotrapezial joint has to be opened, which may result in the development of osteoarthritis, and our results showed that osteoarthritis of this joint was more common in these patients. The clinical relevance of this finding is uncertain, since only a few patients had symptoms, but, more importantly, only $62 \%$ (19 of 30) in the group treated conservatively were available for radiological examination. Although the insertion of a Herbert screw may be difficult, ${ }^{11}$ as occurred in one of our early cases, there were no other technical difficulties.

The major goal of any form of treatment is to achieve early return of function. Apart from the economic aspects, health-related quality of life and early return to function should be considered. Internal fixation allows safe and early return to sports when a cast is not acceptable and when an athlete accepts the risks of surgery. ${ }^{12}$ Those who had an operation had a shorter period of sick leave if in blue-collar occupations, which may be an indirect indication of a quicker return to normal activities. Nevertheless, the long-term functional results were good in both groups.

Internal fixation of an acute fracture of the scaphoid allows early return to normal function and should be regarded as an alternative to conservative treatment in those

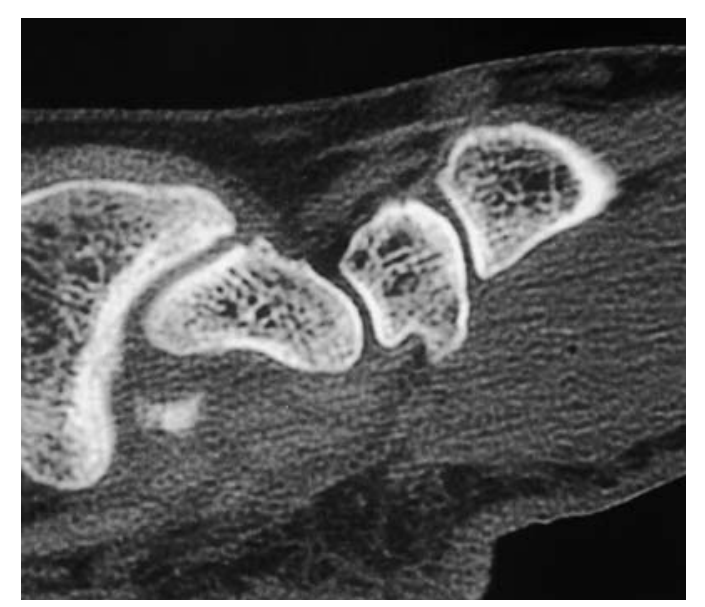

Fig. 3b

CT scans at follow-up at 12 years of a) an operatively treated wrist and b) an uninjured wrist showing osteoarthritis of the scaphotrapezial and radiocarpal joints on the operated side. 
patients who cannot accept immobilisation in a cast for three months or more, for sport, social or work-related reasons.

No benefits in any form have been received or will be received from a commercial party related directly or indirectly to the subject of this article.

\section{References}

1. Rayan GM. Fractures and nonunions of the scaphoid. J Okla State Med Assoc 1996;89:315-23.

2. Ford DJ, Khoury G, El-Hadidi S, Lunn PG, Burke FD. The Herbert screw for fractures of the scaphoid: a review of results and technical difficulties. J Bone Joint Surg [Br] 1987;69-B:124-7.

3. Dias JJ, Brenkel IJ, Finlay DBL. Patterns of union in fractures of the waist of the scaphoid. J Bone Joint Surg [Br] 1989;71-B:307-10.

4. Herndon JH. Scaphoid fractures and complications. Rosemont, American Academy Orthopaedic Surgeons Monograph Series, 1994.
5. Herbert TJ, Fisher WE. Management of the fractured scaphoid using a new bone screw. J Bone Joint Surg [Br] 1984;66-B:114-23.

6. Bunker TD, McNamee PB, Scott TD. The Herbert screw for scaphoid fractures: a multicentre study. J Bone Joint Surg [Br] 1987;69-B:631-4

7. Filan SL, Herbert TJ. Herbert screw fixation of scaphoid fractures. $J$ Bone Joint Surg [Br] 1996;78-B:519-29.

8. Langhoff $\mathbf{O}$, Andersen JL. Consequences of late immobilization of scaphoid fractures. J Hand Surg [Br] 1988;13-B:77-9.

9. Duppe H, Johnell O, Lundborg G, Karlsson M, Redlund-Johnell I. Long-term results of fracture of the scaphoid: a follow-up study of more than thirty years. J Bone Joint Surg [Am] 1994;76-A:249-52.

10. Kozin SH. Internal fixation of scaphoid fractures. Hand Clin 1997;13:573-86.

11. Rettig AC, Kollias SC. Internal fixation of acute stable scaphoid fractures in the athlete. Am J Sports Med 1996;24:182-6.

12. Orthopaedic Trauma Association. Fracture and dislocation compendium. J Orthop Trauma 1996;Suppl10:85-8. 